\title{
PENGARUH CREATIVE TOURISM SAUNG ANGKLUNG UDJO TERHADAP KEPUTUSAN BERKUNJUNG WISATAWAN \\ (Survei pada Pengambil Keputusan Kelompok Rombongan Sekolah Untuk Berkunjung ke Saung Angklung Udjo)
}

\author{
Novika Bellani \\ Gitasiswhara \\ Manajemen Pemasaran Pariwisata FPIPS UPI
}

\begin{abstract}
Bandung city is one of the cities in West Java has potential tourism that can be relied on, and one of the destination in Saung Angklung Udjo. Saung Angklung Udjo offers a package of art and cultural of West Java that attract tourist. The number of tourist visited in Saung Angklung Udjo continue to rised from 2004 until 2010. The increase in the number of tourist are most significant in 2008. Creative tourism is one of the strategy that can be used to increase visitor and continous visitor. In connection with these research conducted that creative tourism in Saung Angklung Udjo influence tourist visit decision. The purpose of this research is to find creative tourism influenced visiting decisions of Saung Angklung Udjo. Technique of sampling is saturated sampling. The method used in this research is explanatory survey by using ordinal scale. Analyze from this research used Path Analysis with a software computer tools SPSS 19.0. The result of this research found Creative Tourism influenced significantly 37,8\% and the rest influence other factors. Based on the result of statictical test were obtained that Creative Spectacles, Creative Spaces, and Creative Tourism has an influence on the decision to visit. It can be conclude that creative spectacles, creative spaces, and creative tourism influence the visiting decision of Saung Angklung Udjo.
\end{abstract}

Key word: Creative Tourism, Visiting Decision

\section{PENDAHULUAN}

\subsection{Latar Belakang}

Pariwisata adalah salah satu jenis industri baru yang mampu mempercepat pertumbuhan ekonomi dan penyediaan lapangan kerja, peningkatan penghasilan, standar hidup serta menstimulasi sektorsektor produktif lainnya. Menurut Pendit (2003:32) menyatakan bahwa "Pariwisata merupakan salah satu jenis industri yang mampu mempercepat pertumbuhan ekonomi dan penyediaan lapangan kerja, peningkatan penghasilan, standar hidup serta menstimulasi sektor-sektor produktif lainnya".

Indonesia secara geografis dan demografis sesungguhnya sangat potensial untuk menjadi daya tarik luar biasa bagi pariwisata internasional, masih banyak kondisi yang terkait upaya untuk meningkatkan pencapaian di sektor pariwisata yang masih harus diperbaiki dan dibenahi di Indonesia meliputi fasilitas dan pra sarana, sumber daya manusia dan sikap mental dalam menyambut atau menerima para wisatawan yang datang. Strategi promosi dan pelayanan pariwisata merupakan aspek yang penting untuk keberhasilan pencapaian pembangunan sektor pariwisata.

Indonesia memiliki potensi alam yang indah dengan budaya dan adat istiadat yang beragam. Pemandangan alam yang indah dan sikap masyarakat yang ramah menjadikan Indonesia sebagai salah satu tempat wisata yang mampu menarik wisatawan baik wisatawan nusantara maupun wisatawan mancanegara untuk berkunjung ke Indonesia.

Indonesia tidak hanya memiliki kekayaan alam yang indah, beragam budaya dan bahasa, Indonesia pun memiliki sekitar 33 provinsi, salah satunya Provinsi Jawa Barat. Sektor pariwisata merupakan salah satu sektor yang potensial untuk dikembangkan di Jawa Barat. Wilayah Provinsi Jawa Barat atau Tatar Sunda, dikenal karena memiliki kekayaan dan keragaman sumber daya pariwisata yang tinggi, meliputi wisata alam, wisata budaya, wisata minat khusus.

Beberapa kota yang memiliki potensi wisata di Jawa Barat seperti Kota Bogor yang mempunyai objek dan daya tarik 
wisata yang unik seperti Kebun Raya Bogor, Tasikmalaya yang memiliki Kampung Naga, juga kota-kota lainnya seperti Cianjur dan Sukabumi, serta kota yang menjadi tujuan utama bagi wisatawan yaitu Bandung.

Pariwisata Kota Bandung terkenal dengan kegiatan belanja dan kuliner. Hal tersebut dapat dilihat dari pesatnya pertumbuhan fasilitas belanja dan kuliner di Kota Bandung. Wisata belanja di Kota Bandung terdapat di daerah Cibaduyut, Binong Jati, Cigondewah, Sarijadi, Cihampelas dan Suci. Kawasan wisata belanja tersebut menawarkan berbagai produk yang menarik, sehingga menjadikan para wisatawan tertarik untuk berkunjung.

Selain menawarkan atraksi wisata kuliner dan belanja juga menawarkan atraksi wisata budaya. Wisata budaya dimaksudkan agar perjalanan yang dilakukan atas dasar keinginan untuk memperluas pandangan hidup seseorang dengan jalan mengadakan kunjungan atau peninjauan ke tempat lain atau ke luar negeri, mempelajari keadaan rakyat, kebiasaan dan adat istiadat mereka, cara hidup mereka, budaya dan seni mereka.

Kota Bandung memiliki berbagai macam objek wisata budaya yang menawarkan produk-produk wisata yang di kemas secara unik sehingga dapat menarik minat para wisatawan untuk berkunjung. Salah satu objek wisata budaya yang ditawarkan oleh Kota Bandung yaitu Saung Angklung Udjo.

Saung Angklung Udjo merupakan sebuah tujuan wisata budaya yang lengkap karena Saung Angklung Udjo memiliki arena pertunjukan, pusat kerajinan bambu dan workshop untuk alat musik bambu. Selain menjadi tujuan wisata bagi warga setempat, tempat ini juga menjadi tujuan para wisatawan mancanegara. Berkaitan dengan hal tersebut, kunjungan wisatawan ke Saung Angklung Udjo adalah sebagai berikut:

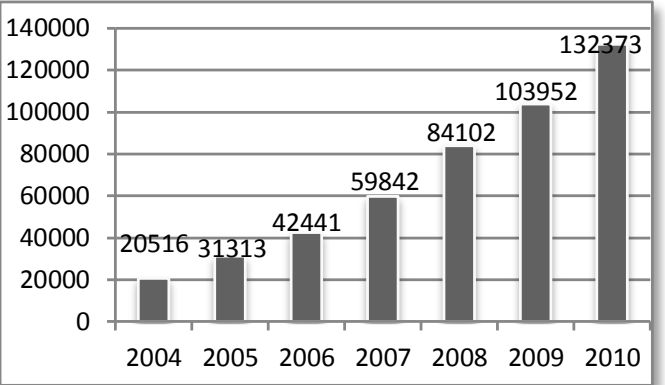

Sumber : Marketing Saung Angklung Udjo, 2010.

\section{GAMBAR 1.1 \\ JUMLAH WISATAWAN SAUNG ANGKLUNG UDJO \\ TAHUN 2004-2010}

Jumlah wisatawan yang berkunjung ke Saung Angklung Udjo tahun 2004-2010 terus mengalami pengingkatan. Peningkatan yang paling signifikan terjadi pada tahun 2008. Pada tahun 2009 dan 2010 pun jumlah kunjungan mengalami kenaikan tetapi tidak sebesar tahun 2008, meskipun jumlahnya tidak sama namun tiap tahun Saung Angklung Udjo selalu mengalami kenaikan jumlah wisatawan.

Melihat jumlah kunjungan wisatawan yang terus meningkat tiap tahunnya maka pihak Saung Angklung Udjo melakukan berbagai macam strategi untuk memberikan pengalaman yang berbeda serta berupaya untuk tetap mempertahankan tingkat kunjungan agar terus meningkat. Strategi yang dilakukan oleh pihak Saung Angklung Udjo dalam mempertahankan tingkat kunjungan wisatawan melalui berbagai program seperti pemasaran yang dilakukan melalui internet dan produk-produk menarik yang ditawarkan, diantaranya membuat angklung sendiri dan angklung tersebut dapat dimainkan pada saat pertunjukan dimulai, serta angklung yang telah dibuat oleh wisatawan tersebut dapat dibawa pulang sebagai cinderamata.

Aktivitas wisata yang dilakukan di Saung Angklung Udjo tidak hanya memberikan pertunjukan yang dapat disaksikan oleh wisatawan, namun didalamnya terdapat aktivitas yang bersifat interaktif yang melibatkan partisipasi penonton. Para penonton atau wisatawan akan disuguhkan pertunjukan seni dan budaya yang dibawakan oleh sekelompok anak-anak kecil yang dihiasi tarian dan kostum yang berwarna-warni. Program yang ditawarkan oleh Saung Angklung Udjo tersebut merupakan suatu bentuk dari kreatifitas yang dapat disebut dengan 
creative tourism. Creative tourism merupakan pariwisata yang menawarkan kesempatan untuk mengembangkan potensi kreatif melalui partisipasi aktif dalam pelatihan dan pengalaman belajar yang disesuaikan dengan karakteristik tempat liburan dimana mereka berada (Raymond \& Richards, 2000:16-20).

Berdasarkan latar belakang di atas, maka perlu diadakan penelitian dengan judul "Pengaruh Creative Tourism Saung Angklung Udjo terhadap Keputusan Berkunjung Wisatawan (Survei pada Pengambil Keputusan Kelompok Rombongan Sekolah untuk Berkunjung Ke Saung Angklung Udjo).

\subsection{Rumusan Masalah}

Berdasarkan latar belakang di atas, maka dapat dirumuskan masalah penelitian sebagai berikut:

1. Sejauh mana creative tourism di Saung Angklung Udjo.

2. Sejauh mana keputusan berkunjung wisatawan di Saung Angklung Udjo.

3. Seberapa besar pengaruh creative tourism Saung Angklung Udjo terhadap keputusan berkunjung wisatawan baik secara simultan atau parsial.

\subsection{Tujuan Penelitian}

Berdasarkan dari rumusan masalah di atas, maka tujuan dari penelitian ini adalah untuk mengetahui:

1. Creative tourism di Saung Angklung Udjo yang terdiri dari creative spectacles, creative spaces, and creative tourism.

2. Keputusan berkunjung wisatawan di Saung Angklung Udjo.

3. Pengaruh creative tourism Saung Angklung Udjo terhadap keputusan berkunjung wisatawan baik secara simultan atau parsial.

\subsection{Kegunaan Penelitian}

Adapun kegunaan dari penelitian ini adalah:

\section{Kegunaan Teoritis}

Hasil penelitian ini diharapkan dapat memperluas kajian ilmu manajemen pemasaran khususnya mengenai creative tourism yang dilakukan dalam mempengaruhi keputusan berkunjung wisatawan, serta diharapkan dari hasil penelitian ini dapat memperluas mengenai ilmu pemasaran pariwisata.

\section{Kegunaan Praktis}

Secara praktis hasil penelitian ini diharapkan dapat memberikan masukan bagi pihak manajemen perusahaan, khususnya bagi Saung Angklung Udjo dalam upaya menarik para wisatawan untuk membuat keputusan berkunjung di Saung Angklung Udjo melalui creative tourism. Diharapkan hasil penelitian ini dapat dijadikan masukan bagi pihak perusahaan dalam upaya mempertahankan tingkat kunjungan dan loyalitas Saung Angklung Udjo.

\section{Kegunaan Lanjutan}

Kegunaan lanjutan dari penelitian ini diharapkan penelitian ini dapat membantu memberikan masukan pada pembaca yang akan melakukan penelitian lebih lanjut mengenai pengaruh creative tourism terhadap keputusan berkunjung.

\section{KERANGKA PEMIKIRAN DAN HIPOTESIS}

\subsection{Kerangka Pemikiran}

Destinasi pariwisata adalah suatu entitas yang mencakup wilayah geografis tertentu yang didalamnya terdapat komponen produk pariwisata (attraction, amenities, accebilities) dan layanan, serta unsur pendukung lainnya. Menurut Ricardson dan Fluker (Pitana dan Diarta, 2009:126), destinasi pariwisata didefinisikan sebagai "A significant place visited on a trip, with some form of actual or perceived boundary. The basic geographic unit for the production of statistics".

Menurut Undang-undang Republik Indonesia No. 10 tahun 2009 mengenai kepariwisataan mengemukakan definisi destinasi pariwisata yaitu kawasan geografis yang berada dalam satu atau lebih wilayah administratif yang di dalamnya terdapat daya tarik wisata, fasilitas umum, fasilitas pariwisata, aksesibilitas, serta masyarakat yang saling terkait dan melengkapi terwujudnya kepariwisataan.

Berdasarkan pengertian destinasi diatas dapat disimpulkan bahwa destinasi pariwisata merupakan suatu wilayah atau kawasan yang dikunjungi dengan waktu yang signifikan dimana didalamnya terdapat 
fasilitas, daya tarik wisata, komponen produk wisata, dan masyarakat yang saling terkait serta unsur pendukung lainnya.

Berjalannya industri pariwisata sangat bergantung pada sumber daya yang tersedia. Dalam konteks pariwisata, sumber daya diartikan sebagai segala sesuatu yang mempunyai potensi untuk dikembangkan guna mendukung pariwisata, baik secara langsung maupun tidak langsung. Sumber daya yang terkait dengan pengembangan pariwisata umumnya berupa sumber daya alam, sumber daya budaya, sumber daya minat khusus, di samping sumber daya manusia. Sumber daya budaya yang bisa dikembangkan menjadi daya tarik wisata diantaranya yaitu bangunan bersejarah, situs monumen, museum, galeri seni, situs budaya kuno, seni dan patung kontemporer, arsitektur, tekstil, pusat kerajinan tangan, seni pertunjukan, drama, sendratari, lagu daerah, festival, dan peninggalan keagamaan seperti pura, candi, masjid, dan sejenisnya.

Seiring dengan berjalannya waktu menjadikan destinasi pariwisata semakin berkembang. Sinergi pertumbuhan pariwisata dan budaya menjadi salah satu pokok utama dalam pengembangan pariwisata dan pemasaran dalam beberapa tahun terakhir. Richards (2001:1) mengemukakan bahwa destinasi pariwisata mencari untuk membedakan diri dari semakin banyaknya jumlah pesaing yang telah berpaling ke budaya sebagai sarana perbedaan, dan budaya semakin dikaitkan dengan pariwisata sebagai sarana pendapatan dan pekerjaan. Pertumbuhan pariwisata budaya telah menjadi salah satu tren utama dalam pariwisata global.

Creative tourism identik dikaitkan dengan wisata budaya. Raymond dan Richards mengidentifikasikan pertumbuhan creative tourism sebagai perluasan dari pariwisata kebudayaan. Konsep kreatifitas merupakan suatu hal yang menarik dalam pariwisata. Konsep tersebut pertama kali diperkenalkan oleh Richards dan Raymond (2000:18) sebagai sebuah bentuk pariwisata yang menawarkan kesempatan untuk mengembangkan potensi kreatif melalui partisipasi aktif dalam pelatihan dan pengalaman belajar yang disesuaikan dengan karakteristik tempat liburan dimana mereka berada. Creative tourism secara eksplisit menyediakan tujuan wisata dengan kesempatan untuk terlibat dengan budaya lokal mereka dalam rangka untuk menawarkan pengalaman yang unik.
Catriona Campbell mendefinisikan creative tourism sebagai kegiatan wisata yang menawarkan pengunjung suatu pengajaran kreatif (termasuk seni, kerajinan dan lokakarya masakan), dengan kesempatan untuk tinggal di akomodasi berkualitas tinggi, dan untuk berhubungan dengan orang lokal di tempat tujuan yang berbeda.

Berdasarkan beberapa definisi mengenai creative tourism yang telah dikemukakan oleh para ahli di atas dapat disimpulkan bahwa creative tourism merupakan sebuah kegiatan pariwisata dimana para wisatawan dapat mengembangkan potensi kreatif mereka melalui partisipasi aktif di dalam pengalaman belajar seni, warisan atau karakter khusus dari tempat yang dikunjungi.

Definisi-definisi creative tourism berdasarkan pendapat dari beberapa ahli tersebut dapat membedakan creative tourism dengan jenis pariwisata lain. Creative tourism muncul dari adanya produk-produk pariwisata yang memiliki potensi tinggi dan memiliki perbedaan dengan produk-produk wisata lainnya yang serupa, sehingga produk tersebut dapat dikatakan kreatif dan menjadi pelengkap dari sektor pariwisata yang mampu menambah pendapatan devisa bagi suatu daerah.

Berbagai cara penerapan kreatifitas dalam membantu mengembangkan pariwisata budaya menjadi creative tourism telah ditunjukkan oleh Richards dan Raymond (2006:131) yang membagi creative tourism menjadi tiga bagian yaitu:

a. Creative spectacles: suatu pengalaman kreatif yang di konsumsi oleh wisatawan pasif.

b. Creative spaces: pengembangan kawasan kreatif yang dihuni oleh orang-orang kreatif untuk menarik pengunjung.

c. Creative tourism: sebuah keterlibatan yang lebih aktif para wisatawan, tidak hanya melihat atau menonton tapi berinteraksi secara aktif.

Perbedaan utama dari creative spectacles, creative spaces, dan creative tourism yaitu creative tourism lebih tergantung pada partisipasi aktif wisatawan pada suatu objek wisata. Namun ketiga hal tersebut sangat penting untuk dilakukan oleh objek wisata, terutama yang bergerak pada wisata budaya, dimana para wisatawan yang 
berkunjung dapat berpartisipasi secara aktif dalam perjalanan wisata seperti mempelajari adat dan budaya pada tempat yang dikunjungi oleh wisatawan.

Richards dan Raymond (Ozen Kirant Yozcu dan Orhan Icoz, 2010) pun medefinisikan creative tourism sebagai belajar keterampilan pada hari libur yang merupakan bagian dari budaya negara atau masyarakat yang dikunjungi. Wisatawan kreatif mengembangkan potensi kreatif mereka dan lebih dekat dengan masyarakat setempat melalui partisipasi informal di workshop interaktif dan pengalaman belajar budaya yang menarik dari tujuan liburan mereka

(http://creativetourism.co.nz/aboutus_oursto ry). Raymond menunjukkan bahwa workshop interaktif yang terjadi di kelompok-kelompok kecil di rumah pendidik dan tempat kerja, memungkinkan pengunjung untuk mengeksplorasi kreativitas mereka untuk lebih dekat dengan masyarakat setempat. Workshop ini biasanya termasuk dari nilai tujuan seperti seni, budaya, dan alam (Raymond, 2007).

Keputusan berkunjung dalam penelitian ini diadaptasi dari keputusan pembelian karena tahap-tahap yang dilewati oleh wisatawan menentukan pilihan destinasi wisata sama dengan tahap keputusan pembelian pada umumnya. Buchari Alma (2008:63) mendefinisikan keputusan pembelian adalah suatu keputusan yang dilakukan oleh konsumen yang dipengaruhi oleh kebudayaan, kelas sosial, keluarga, dan referensi grup yang akan membentuk suatu sikap pada diri individu kemudian melakukan pembelian. Definisi keputusan pembelian menurut Kotler dan Amstrong (2008:457) bahwa keputusan pembelian merupakan proses keputusan dimana konsumen benar-benar memutuskan untuk membeli salah satu produk diantara berbagai macam alternatif pilihan.

Berdasarkan pendapat dari beberapa ahli di atas dapat disimpulkan bahwa keputusan berkunjung merupakan suatu proses wisatawan pada saat memutuskan untuk memilih menggunakan produk atau jasa melalui berbagai alternatif pilihan yang diberikan oleh perusahaan.

Pada titik tertentu seorang wisatawan harus dapat memutuskan antara berkunjung atau tidak berkunjung. Bila perlu, dalam keputusan berkunjung wisatawan tersebut dapat memperoleh alternatif yang dipilih atau pengganti yang diterima. Menurut
Cooper et.al dalam Ismayanti (2010:28) variabel eksternal dalam keputusan berkunjung berwisata terdiri dari kredibilitas Biro Perjalanan Wisata, citra destinasi, pengalaman berwisata, tujuan berwisata, waktu dan biaya. Dalam penelitian ini hanya empat indikator yang akan diteliti yaitu citra destinasi, pengalaman berwisata, tujuan berwisata, waktu dan biaya.

Berdasarkan uraian di atas maka dapat digambarkan kerangka pemikiran mengenai program creative tourism terhadap keputusan berkunjung pada Gambar 2.1 di bawah ini. 


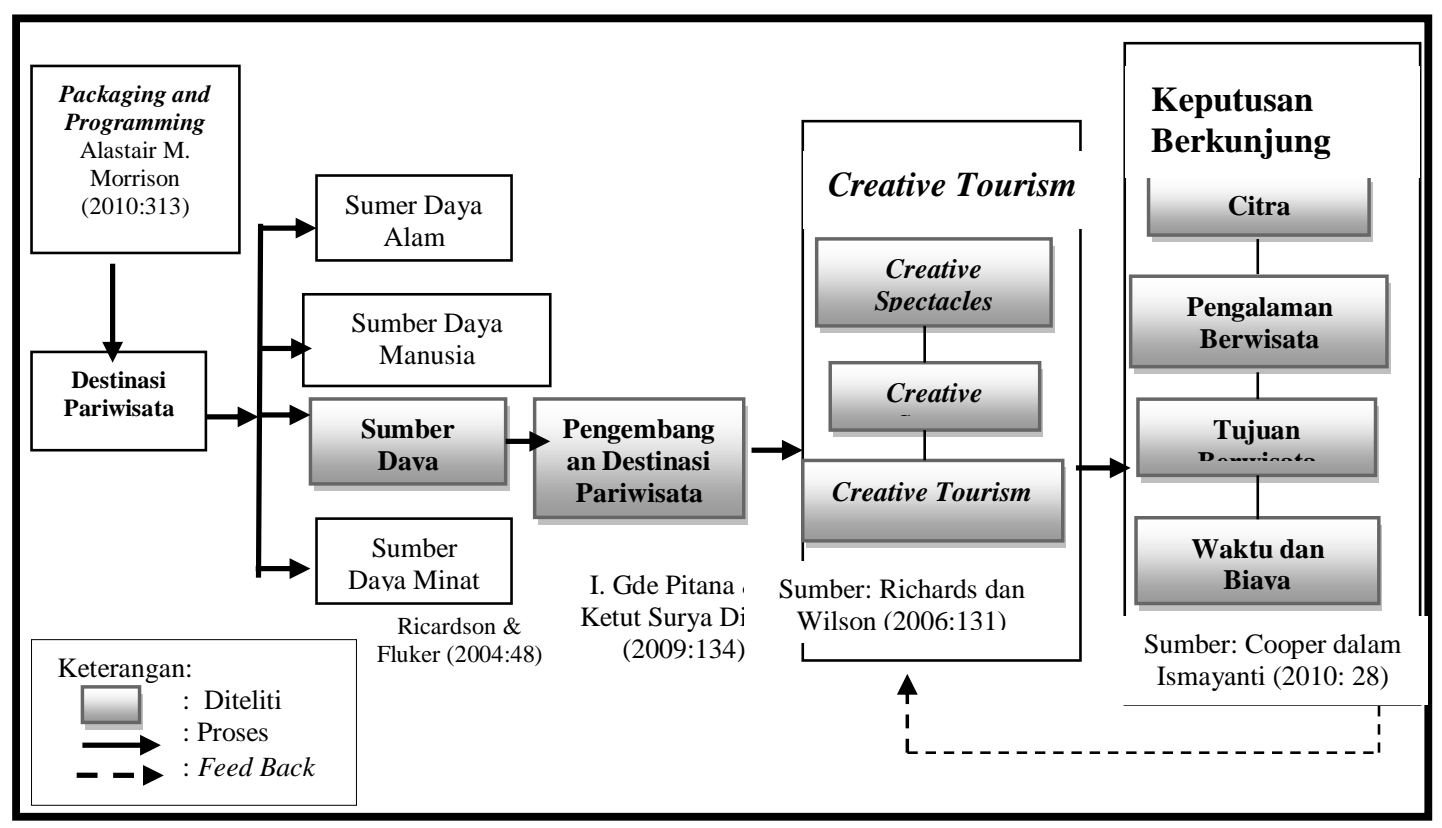

GAMBAR 2.1

KERANGKA PEMIKIRAN PENGARUH CREATIVE TOURISM SAUNG ANGKLUNG UDJO TERHADAP KEPUTUSAN BERKUNJUNG WISATAWAN

\subsection{Hipotesis Penelitian}

Hipotesis memegang peranan yang penting dalam suatu penelilitian maka peneliti dalam menyusun hipotesis ini di dukung oleh premis-premis sebagai berikut :

1. Richards dan Raymond (2000)

Sebagai bentuk pariwisata yang menawarkan kesempatan kepada pengunjung untuk mengembangkan potensi kreatif mereka melalui partisipasi aktif dalam program dan pengalaman belajar yang merupakan karakteristik tujuan liburan yang mereka lakukan.

2. Richards dan Raymond (2010)

Creative tourism sebagai belajar keterampilan pada hari libur yang merupakan bagian dari budaya negara atau masyarakat yang dikunjungi.

3. Catriona Campbell (2010)

Mendefinisikan creative tourism sebagai kegiatan wisata yang menawarkan pengunjung suatu pengajaran kreatif (termasuk seni, kerajinan dan lokakarya masakan), dengan kesempatan untuk tinggal di akomodasi berkualitas tinggi, dan untuk berhubungan dengan orang lokal di tempat tujuan yang berbeda.
Berdasarkan beberapa teori yang telah dijelaskan dan berdasarkan kerangka pemikiran yang telah dianut di atas, maka penulis merumuskan hipotesis untuk penelitian ini yaitu terdapat pengaruh secara positif dari creative tourism terhadap keputusan berkunjung ke Saung Angklung Udjo baik secara simultan maupun parsial.

\section{OBJEK DAN METODE} PENELITIAN

\subsection{Objek Penelitian}

Dalam penelitian ini, penulis akan meneliti tentang pengaruh creative tourism di Saung Angklung Udjo terhadap Keputusan Berkunjung. Penelitian ini terdiri dari satu variabel bebas (independent variable) dan satu variabel terikat (dependent variable). Variabel independen adalah variabel yang mempengaruhi baik secara positif maupun negatif terhadap variabel dependen, sedangkan variabel dependen adalah variabel yang dipengaruhi oleh variabel lain. Adapun yang menjadi objek penelitian sebagai variabel bebas adalah creative tourism (X) yang terdiri dari beberapa sub variabel yaitu creative spectacles, creative spaces, dan creative tourism. Objek penelitian sebagai variabel terikat adalah keputusan berkunjung (Y) yang terdiri dari sub variabel diantaranya 
citra destinasi, pengalaman berwisata, tujuan berwisata, waktu dan biaya.

Responden yang menjadi unit analisis dari penelitian ini adalah pengambil keputusan kelompok rombongan sekolah untuk berkunjung ke Saung Angklung Udjo.

\subsection{Metode Penelitian}

\subsubsection{Jenis Penelitian dan Metode yang Digunakan}

Sugiyono (2008:11) mendefinisikan bahwa penelitian deskriptif adalah penelitian yang dilakukan untuk mengetahui nilai variabel mandiri, baik satu variabel atau lebih tanpa membuat perbandingan atau menghubungkan dengan variabel lain. Penelitian deskriptif disini bertujuan untuk memperoleh deskripsi tentang permasalahan yang diteliti. Penelitian deskriptif disini bertujuan untuk memperoleh deskripsi atau gambaran mengenai promosi dan bagaimana creative tourism tersebut dapat berpengaruh pada keputusan berkunjung.

Penelitian verifikatif menurut Suharsimi Arikunto (2009:8) merupakan "Penelitian yang pada dasarnya ingin menguji kebenaran melalui pengumpulan data di dalam lapangan". Dalam penelitian ini akan diuji mengenai kebenaran hipotesis melalui pengumpulan data di lapangan, dalam penelitian ini di uji creative tourism dalam mempertahankan keputusan berkunjung di Saung Angklung Udjo.

Berdasarkan jenis penelitian deskriptif, metode penelitian yang digunakan adalah metode deskriptif survey dan metode explanatory survey untuk menjelaskan hubungan antara variabel-variabel melalui pengujian hipotesis. Metode tersebut dipergunakan untuk menjelaskan hubungan antara variabel-variabel penelitian melalui pengujian hipotesis. Menurut Sugiyono (2008:11) yang dimaksud dengan metode survei yaitu:

Metode survei digunakan untuk mendapatkan data dari tempat tertentu yang alamiah (bukan buatan), tetapi peneliti melakukan perlakuan dalam pengumpulan data, misalnya dengan mengedarkan kuesioner, test, wawancara terstruktur dan sebagainya (perlakuan tidak seperti dalam eksperimen).

Metode pengembangan yang dipergunakan adalah cross-sectional method. Menurut Husein Umar (2009:42), cross sectional method yaitu metode penelitian dengan cara meneliti suatu fenomena tertentu dalam satu kurun waktu saja.

\subsection{Operasionalisasi Variabel}

Penelitian ini meliputi dua variabel initi, yaitu variabel bebas dan variabel terikat. Variabel creative tourism disebut sebagai variabel bebas (X) yang memiliki dimensi creative spectacles, creative spaces, dan creative tourism. Variabel keputusan berkunjung disebut sebagai variabel terikat (Y) yang terdiri dari citra destinasi, pengalaman berwisata, tujuan berwisata, waktu dan biaya.

TABEL 3.1

OPERASIONALISASI VARIABEL PENELITIAN

\begin{tabular}{|l|l|c|c|c|c|}
\hline $\begin{array}{c}\text { Variabel/ } \\
\text { Sub } \\
\text { Variabel }\end{array}$ & Konsep Variabel & Indikator & Ukuran & Skala & $\begin{array}{c}\text { No. } \\
\text { Item }\end{array}$ \\
\hline \multicolumn{1}{|c|}{$\mathbf{1}$} & \multicolumn{1}{|c|}{$\mathbf{2}$} & $\mathbf{3}$ & $\mathbf{4}$ & $\mathbf{5}$ & $\mathbf{6}$ \\
\hline $\begin{array}{l}\text { Courive } \\
(\mathrm{X})\end{array}$ & $\begin{array}{l}\text { Pariwisata yang } \\
\text { menawarkan } \\
\text { kesempatan } \\
\text { kepada para } \\
\text { pengunjung untuk } \\
\text { mengembangkan } \\
\text { potensi kreatif } \\
\text { mereka melalui } \\
\text { partisipasi aktif di } \\
\text { dalam } \\
\text { pengalaman- } \\
\text { pengalaman } \\
\text { belajar dan } \\
\text { pelajaran yang } \\
\text { merupakan } \\
\text { karakteristik dari }\end{array}$ & & & & \\
& & & & \\
\hline
\end{tabular}




\begin{tabular}{|c|c|c|c|c|c|}
\hline $\begin{array}{c}\text { Variabel/ } \\
\text { Sub } \\
\text { Variabel }\end{array}$ & Konsep Variabel & Indikator & Ukuran & Skala & $\begin{array}{l}\text { No. } \\
\text { Item }\end{array}$ \\
\hline & $\begin{array}{l}\text { tempat tujuan } \\
\text { liburan dimana } \\
\text { pengalaman- } \\
\text { pengalaman } \\
\text { tersebut } \\
\text { diusahakan. } \\
\text { (Richards \& } \\
\text { Raymond, } \\
\text { 2000:16-20) }\end{array}$ & & & & \\
\hline $\begin{array}{l}\text { Creative } \\
\text { Spectacles } \\
\text { (X.1) }\end{array}$ & $\begin{array}{l}\text { Suatu pengalaman } \\
\text { kreatif yang di } \\
\text { konsumsi oleh } \\
\text { wisatawan pasif }\end{array}$ & Performance & $\begin{array}{l}\text { - Tingkat } \\
\text { kemenarikan } \\
\text { pertunjukan } \\
\text { - Tingkat } \\
\text { keanekaragama } \\
\text { n pertunjukan } \\
\text { - Tingkat } \\
\text { keunikan } \\
\text { pertunjukan } \\
\text { - Tingkat } \\
\text { keunggulan } \\
\text { pertunjukan } \\
\text { - Tingkat keaslian } \\
\text { pertunjukan }\end{array}$ & $\begin{array}{l}\text { Ordinal } \\
\text { Ordinal } \\
\text { Ordinal } \\
\text { Ordinal } \\
\text { Ordinal }\end{array}$ & $\begin{array}{l}\text { B.I.1 } \\
\text { B.I.2 } \\
\text { B.I.3 } \\
\text { B.I.4 } \\
\text { B.I.5 }\end{array}$ \\
\hline \multirow[t]{2}{*}{$\begin{array}{l}\text { Creative } \\
\text { Spaces } \\
(X .2)\end{array}$} & \multirow[t]{2}{*}{$\begin{array}{l}\text { Pengembangan } \\
\text { kawasan kreatif } \\
\text { yang dihuni oleh } \\
\text { orang-orang } \\
\text { kreatif untuk } \\
\text { menarik } \\
\text { pengunjung }\end{array}$} & - Atmosphere & $\begin{array}{l}\text { - Tingkat } \\
\text { kenyamanan } \\
\text { ruang } \\
\text { pertunjukan } \\
\text { - Tingkat } \\
\text { keasrian objek } \\
\text { wisata Saung } \\
\text { Angklung Udjo }\end{array}$ & $\begin{array}{l}\text { Ordinal } \\
\text { Ordinal }\end{array}$ & $\begin{array}{l}\text { B.II.6 } \\
\text { B.II.7 }\end{array}$ \\
\hline & & - Design & $\begin{array}{l}\text { Tingkat } \\
\text { kemenarikan } \\
\text { desain eksterior } \\
\text { objek wisata } \\
\text { Saung } \\
\text { Angklung Udjo } \\
\text { - Tingkat } \\
\text { kemenarikan } \\
\text { interior ruangan } \\
\text { pertunjukan }\end{array}$ & Ordinal & B.II.8 \\
\hline $\begin{array}{l}\text { Creative } \\
\text { Tourism } \\
(X .3)\end{array}$ & $\begin{array}{l}\text { Sebuah } \\
\text { keterlibatan yang } \\
\text { lebih aktif para } \\
\text { wisatawan, tidak } \\
\text { hanya melihat } \\
\text { atau menonton } \\
\text { tapi berinteraksi } \\
\text { secara aktif }\end{array}$ & - Co-makership & $\begin{array}{l}\text { - Tingkat } \\
\text { kegiatan seni } \\
\text { interaktif pada } \\
\text { saat } \\
\text { pertunjukan } \\
\text { - Tingkat } \\
\text { pengetahuan } \\
\text { yang } \\
\text { didapatkan } \\
\text { - Tingkat } \\
\text { interaksi dalam } \\
\text { pembuatan } \\
\text { produk } \\
\text { - Tingkat }\end{array}$ & $\begin{array}{l}\text { Ordinal } \\
\text { Ordinal } \\
\text { Ordinal } \\
\text { Ordinal } \\
\text { Ordinal }\end{array}$ & $\begin{array}{l}\text { B.III.10 } \\
\text { B.III.11 } \\
\text { B.III.12 } \\
\text { B.III.13 } \\
\text { B.III.14 }\end{array}$ \\
\hline
\end{tabular}




\begin{tabular}{|c|c|c|c|c|c|}
\hline $\begin{array}{c}\text { Variabel/ } \\
\text { Sub } \\
\text { Variabel }\end{array}$ & Konsep Variabel & Indikator & Ukuran & Skala & $\begin{array}{l}\text { No. } \\
\text { Item }\end{array}$ \\
\hline & & & $\begin{array}{l}\text { kemenarikan } \\
\text { pada saat } \\
\text { interaksi } \\
\text { pembuatan } \\
\text { produk } \\
\text { - Tingkat } \\
\text { pengetahuan } \\
\text { instruktur pada } \\
\text { saat interaksi } \\
\text { pembuatan } \\
\text { produk }\end{array}$ & & \\
\hline
\end{tabular}

\begin{tabular}{|c|c|c|c|c|c|}
\hline \multirow[t]{3}{*}{$\begin{array}{l}\text { Keputusan } \\
\text { berkunjung }\end{array}$} & $\begin{array}{l}\text { Keputusan } \\
\text { berkunjung adalah } \\
\text { suatu proses yang } \\
\text { berawal pada } \\
\text { keinginan dan } \\
\text { kebutuhan, } \\
\text { dilanjutkan dengan } \\
\text { tahap pencarian } \\
\text { informasi yang } \\
\text { berdasarkan } \\
\text { informasi yang } \\
\text { didapatkan dari } \\
\text { seorang wisatawan } \\
\text { untuk } \\
\text { membayangkan } \\
\text { kondisi aktual } \\
\text { daerah tujuan } \\
\text { wisata. } \\
\text { (Cooper dalam } \\
\text { Ismayanti, } \\
\text { 2010:28) }\end{array}$ & & & & \\
\hline & & $\begin{array}{l}\text { Citra } \\
\quad \text { Destinasi }\end{array}$ & $\begin{array}{l}\text { Tingkat citra } \\
\text { objek wisata } \\
\text { dimata } \\
\text { masyarakat } \\
\text { - Tingkat } \\
\text { pengetahuan } \\
\text { wisatawan } \\
\text { terhadap objek } \\
\text { wisata sebagai } \\
\text { objek wisata } \\
\text { seni dan budaya }\end{array}$ & $\begin{array}{l}\text { Ordinal } \\
\text { Ordinal }\end{array}$ & $\begin{array}{l}\text { C.II.1 } \\
\text { C.II.2 }\end{array}$ \\
\hline & & $\begin{array}{r}\text { Pengalaman } \\
\text { Berwisata }\end{array}$ & $\begin{array}{ll}\text { - } & \text { Tingkat } \\
\text { pengalaman } \\
\text { berwisata yang } \\
\text { menyenangkan } \\
\text { - Tingkat } \\
\text { kenangan } \\
\text { berwisata yang } \\
\text { menyenangkan } \\
\text { - Tingkat } \\
\text { kesesuaian yang }\end{array}$ & $\begin{array}{l}\text { Ordinal } \\
\text { Ordinal } \\
\text { Ordinal }\end{array}$ & $\begin{array}{l}\text { C.III.3 } \\
\text { C.III.4 } \\
\text { C.III.5 }\end{array}$ \\
\hline
\end{tabular}




\begin{tabular}{|c|c|c|c|c|c|}
\hline & & & $\begin{array}{l}\text { diharapkan } \\
\text { dengan yang } \\
\text { didapat }\end{array}$ & & \\
\hline & & $\begin{array}{l}\text { Tujuan } \\
\text { Berwisata }\end{array}$ & \begin{tabular}{|l} 
- \\
Tingkat tujuan \\
untuk melihat \\
seni dan budaya \\
di objek wisata \\
- Tingkat tujuan \\
untuk \\
mengetahui seni \\
dan budaya di \\
objek wisata \\
- Tingkat untuk \\
meneiti seni dan \\
budaya di objek \\
wisata \\
Tingkat tujuan \\
untuk \\
menikmati seni \\
dan budaya di \\
objek wisata
\end{tabular} & $\begin{array}{l}\text { Ordinal } \\
\text { Ordinal } \\
\text { Ordinal } \\
\text { Ordinal }\end{array}$ & $\begin{array}{l}\text { C.IV.6 } \\
\text { C.IV.7 } \\
\text { C.IV.8 } \\
\text { C.IV.9 }\end{array}$ \\
\hline & & Waktu & $\begin{array}{ll}\text { - } & \text { Tingkat } \\
\text { berkunjung } \\
\text { pada saat } \\
\text { liburan } \\
\text { - } \text { Tingkat } \\
\text { berkunjung } \\
\text { pada saat } \\
\text { mengisi waktu } \\
\text { luang }\end{array}$ & $\begin{array}{l}\text { Ordinal } \\
\text { Ordinal }\end{array}$ & $\begin{array}{l}\text { C.V.10 } \\
\text { C.V.11 }\end{array}$ \\
\hline & & Biaya & \begin{tabular}{|l} 
Tingkat \\
kesesuaian \\
biaya yang \\
dikeluarkan \\
dengan \\
kesenangan \\
yang didapat \\
- Tingkat \\
kesesuaian \\
biaya yang \\
dikeluarkan \\
dengan \\
pengalaman \\
yang didapat \\
Tingkat \\
ketepatan biaya \\
yang \\
dikeluarkan \\
dengan \\
kenyataan. \\
\end{tabular} & $\begin{array}{l}\text { Ordinal } \\
\text { Ordinal } \\
\text { Ordinal }\end{array}$ & $\begin{array}{l}\text { C.VI.12 } \\
\text { C.VI.13 } \\
\text { C.VI.14 }\end{array}$ \\
\hline
\end{tabular}




\subsubsection{Metode Penarikan Sampel}

Sampel dalam penelitian ini yaitu pengambil keputusan untuk berkunjung ke Alam Saung Angklung Udjo. Jumlah sampel yang diambil dalam penelitian ini sebesar 70 sampel dari jumlah populasi kelompok rombongan sekolah yang terdiri dari rombongan sekolah formal dan informal, serta pelajar dan mahasiswa yang mengatur sendiri perjalanannya ke Saung Angklung Udjo tahun 2010 sebanyak 401 rombongan dengan menggunakan rumus Renckly.

\subsubsection{Prosedur Pengumpulan Data}

Pengumpulan data yang dilakukan penulis menggunakan teknik sebagai berikut.:

1. Wawancara

2. Observasi

3. Studi dokumentasi

4. Studi literatur

5. Angket/kuesioner

\subsection{Pengujian Hipotesis}

Teknik untuk menguji data yang digunakan dalam penelitian kuantitatif ini adalah metode analisis verifikatif. maka dilakukan analisis jalur (path analysis). Dalam Hal ini jalur yang digunakan untuk menentukan besarnya variabel indipenden $\left(\mathrm{X}_{1}, \mathrm{X}_{2}, \mathrm{X}_{3}\right)$ dimana creative spectacles sebagai $\mathrm{X}_{1}$, creative spaces $\mathrm{X}_{2}$, dan creative tourism $\mathrm{X}_{3}$ terhadap $\mathrm{Y}$ baik secara langsung maupun tidak langsung. Pengujian hipotesis dilakukan dengan menggambar struktur hipotesis.

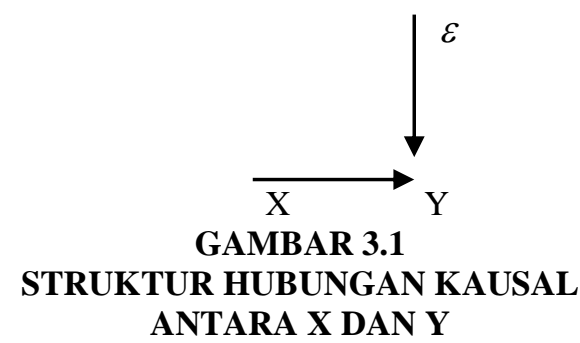

Struktur Hubungan antara X dan Y diuji melalui analisis jalur dengan hipotesis yang berbunyi terdapat pengaruh yang signifikan antara creative tourism yang terdiri dari creative spectacles $\left(\mathrm{X}_{1}\right)$, creative spaces $\left(\mathrm{X}_{2}\right)$, dan creative tourism $\left(\mathrm{X}_{3}\right)$ dan keputusan berkunjung (Y). Selanjutnya struktur hubungan diatas diterjemahkan kedalam hipotesis yang menyatakan pengaruh variabel bebas yang dominan terhadap variabel terikat. Untuk lebih jelas dapat dilihat pada Gambar 3.2 berikut.

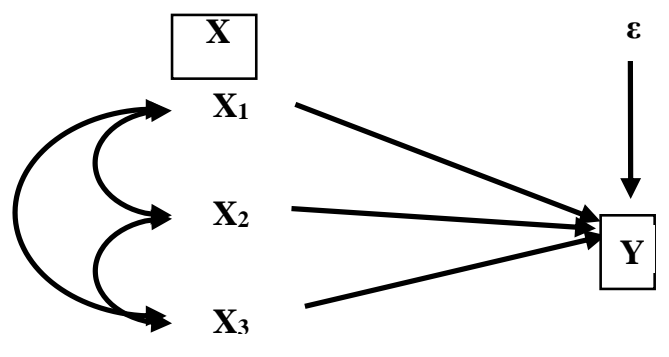

GAMBAR 3.2

DIAGRAN JALUR STRUKTUR HIPOTESIS UTAMA

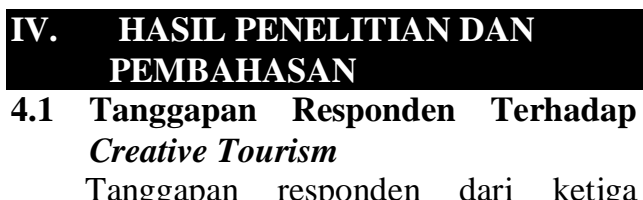
creative tourism yaitu creative spectacles, creative spaces, dan creative tourism yang tertinggi adalah mengenai creative tourism yaitu sebesar 35,34\%. Hal tersebut dikarenakan paket pertunjukan yang ditawarkan oleh Saung Angklung Udjo sangat menarik, dimana didalamnya terdapat aktivitas wisata yang melibatkan partisipasi aktif dari wisatawan. Sedangkan tanggapan responden terendah yaitu creative spaces yaitu sebesar $31,95 \%$. Hal tersebut dikarenakan tujuan para wisatawan yang berkunjung ke Saung Angklung Udjo yaitu untuk melihat dan menikmati petunjukan yang ditawarkan, sehingga mereka memberikanpenilaian yang kurang untuk desain interior ataupun eksterior di Saung Angklung Udjo.

\subsection{Tanggapan Responden Terhadap Keputusan Berkunjung}

Tanggapan responden dari keempat keputusan berkunjung yaitu citra destinasi, pengalaman berwisata, tujuan berwisata, waktu dan biaya yang tertinggi adalah mengenai pengalaman berwisata yaitu sebesar $18,19 \%$. Hal ini dikarenakan paket pertunjukan yang ditawarkan sangat menarik, sehingga hal tersebut menjadikan para wisatawan mendapatkan pengalaman berwisata yang menyenangkan dan ingin kembali melakukan kunjungan ke Saung Angklung Udjo. Sedangkan tanggapan responden yang terendah adalah waktu berkunjung yaitu sebesar 13,75\%. Hal tersebut dikarenakan keputusan berkunjung wisatawan berbeda-beda sesuai dengan kapan wisatawan tersebut membutuhkan. 


\subsection{Pengaruh Creative Tourism Terhadap} Keputusan Berkunjung

Pengujian hipotesis untuk menguji besarnya pengaruh creative tourism yang terdiri dari creative spectacles (X1.1), creative spaces (X1.2), dan creative tourism (X1.3) terhadap keputusan berkunjung (Y). Hasil korelasi antara creative tourism dengan keputusan berkunjung dalam Tabel 5 berikut ini:

TABEL 4.1

MATRIKS KORELASI ANTARA SUB

VARIABEL CREATIVE TOURISM DENGAN KEPUTUSAN BERKUNJUNG

\begin{tabular}{|c|c|c|c|c|}
\hline & $\mathbf{Y}$ & $\mathbf{X 1 . 1}$ & $\mathbf{X 1 . 2}$ & $\mathbf{X 1 . 3}$ \\
\hline $\mathbf{Y}$ & 1 & $-0,075$ & 0,095 & 0,415 \\
\hline $\mathbf{X 1 . 1}$ & $-0,075$ & 1 & 0,601 & 0,121 \\
\hline $\mathbf{X 1 . 2}$ & 0,095 & 0,601 & 1 & $-0,022$ \\
\hline $\mathbf{X 1 . 3}$ & 0,415 & 0,121 & $-0,022$ & 1 \\
\hline
\end{tabular}

Sumber: Hasil Pengolahan Data, 2010

Berdasarkan matriks korelasi antara sub variabel creative tourism terhadap keputusan berkunjung diperoleh hasil korelasi secara berurutan yaitu, creative spectacles $(-0,075)$, creative spaces $(0,095)$, dan creative tourism $(0,415)$. Berikut disajikan pengujian koefisien jalur setiap sub variabel creative tourism dan kontribusi secara langsung maupun tidak langsung setiap sub variabel creative tourism terhadap keputusan berkunjung pada tabel berikut.

TABEL 4.2

HASIL PENGUJIAN KOEFISIEN

JALUR SERTA PENGARUH

LANGSUNG DAN TIDAK LANGSUNG

VARIABEL CREATIVE TOURISM

TERHADAP KEPUTUSAN BERKUNJUNG

\begin{tabular}{|c|c|c|c|c|c|c|c|c|}
\hline \multirow[b]{2}{*}{$X$} & $\begin{array}{c}\text { Pe } \\
\text { ng } \\
\text { aru } \\
\mathrm{h}\end{array}$ & \multicolumn{3}{|c|}{$\begin{array}{l}\text { Pengaruh } \\
\text { Tidak } \\
\text { Langsung } \\
\text { Melalui }\end{array}$} & \multirow[b]{2}{*}{$\begin{array}{l}\mathrm{R}^{2} \mathrm{Y} \\
\mathrm{X} 1.1, \ldots \\
\ldots \mathrm{YX} 1 \\
.5\end{array}$} & \multirow[b]{2}{*}{$\begin{array}{l}\mathrm{t}_{\mathrm{hi}} \\
\text { tu } \\
\mathrm{ng}\end{array}$} & \multirow[b]{2}{*}{$\begin{array}{l}\text { S } \\
\text { ig }\end{array}$} & \multirow[b]{2}{*}{$\begin{array}{c}\mathrm{Ke} \\
\text { put } \\
\text { usa } \\
\mathrm{n}\end{array}$} \\
\hline & $\begin{array}{l}\mathrm{La} \\
\text { ng } \\
\text { su } \\
\text { ng } \\
\text { ter } \\
\text { ha } \\
\text { da } \\
\text { p } \\
\mathrm{Y}\end{array}$ & $\begin{array}{l}\mathrm{X} \\
1 . \\
1\end{array}$ & $\begin{array}{l}X \\
1 . \\
2\end{array}$ & $\begin{array}{l}X \\
1 . \\
3\end{array}$ & & & & \\
\hline $\begin{array}{c}\mathrm{X} \\
1\end{array}$ & $\begin{array}{l}0,0 \\
93\end{array}$ & - & $\begin{array}{l}- \\
0 \\
0 \\
0 \\
4 \\
2\end{array}$ & $\begin{array}{l}0, \\
0 \\
1 \\
7\end{array}$ & $\begin{array}{c}0,06 \\
8\end{array}$ & $\begin{array}{l}- \\
2, \\
2 \\
3 \\
2\end{array}$ & $\begin{array}{l}0, \\
0 \\
2 \\
9\end{array}$ & $\begin{array}{c}\text { Ho } \\
\text { dit } \\
\text { ola } \\
k\end{array}$ \\
\hline $\mathrm{X}$ & 0,0 & - & - & - & 0,00 & 2 & 0 , & Ho \\
\hline
\end{tabular}

\begin{tabular}{|c|c|c|c|c|c|c|c|c|}
\hline 1 & 52 & 0, & & 0, & 8 & 1 & 0 & dit \\
. & & 0 & & 0 & & 3 & 3 & ola \\
2 & & 4 & & 0 & & 2 & 7 & $\mathrm{k}$ \\
& & 2 & & 2 & & & & \\
\hline $\mathrm{X}$ & 0,2 & - & - & - & 0,20 & 4, & 0, & Ho \\
1 & 28 & 0, & 0, & & 9 & 2 & 0 & dit \\
ola \\
3 & & 0 & 0 & & & 0 & 0 & 0 \\
3 & & 1 & 0 & & & 8 & 0 & $\mathrm{k}$ \\
& & 7 & 2 & & & & & \\
\hline $\mathrm{R}$ & & & & & 0.37 & & & \\
2 & & & & & 8 & & & \\
\hline
\end{tabular}

Sumber: Hasil Pengolahan Data, 2010

Pengujian hipotesis melalui uji signifikansi dan uji-t menghasilkan penolakan terhadap Ho untuk creative spectacles, creative spaces, dan creative tourism, karena nilai signifikansi lebih kecil dibandingkan dengan 0,1. Hal tersebut berarti bahwa terdapat pengaruh yang signifikan antara creative spectacles, creative spaces, dan creative tourism terhadap keputusan berkunjung. Berdasarkan hasil perhitungan di atas dapat diketahui bahwa pengaruh creative tourism terhadap keputusan berkunjung adalah sebesar 0,378, sedangkan koefisien jalur variabel lain di luar variabel creative tourism yaitu creative spectacles, creative spaces, dan creative tourism ditentukan melalui:

$$
\begin{aligned}
& P_{Z \varepsilon}=\sqrt{1-R_{Y(X 1.1, \ldots X 1.5)}^{2}} \\
& =\sqrt{1-0,378} \\
& =0,7886
\end{aligned}
$$

Hal tersebut berarti bahwa X1.1 sampai X1.3 bersama-sama mempengaruhi keputusan berkunjung sebesar $37,88 \%$ dan sisanya sebesar $(0,7886)^{2}=0,6218 \times 100 \%$ $=62,18 \%$ dipengaruhi faktor lain yang tidak masuk ke dalam penelitian ini seperti program pemasaran di Saung Angklung Udjo.

\section{KESIMPULAN}

Berdasarkan hasil penelitian secara deskriptif dan verifikatif dapat disimpulkan sebagai berikut:

1. Creative tourism di Saung Angklung Udjo terdiri dari creative spectacles, creative spaces dan creative tourism. Dari aspek tersebut, creative tourism mendapatkan penilaian skor tertinggi dibandingkan dengan aspek lain. Hal ini dikarenakan creative tourism merupakan kegiatan wisata yang melibatkan partisipasi aktif dari 
wisatawan,. Para wisatawan yang berkunjung tidak hanya melihat pertunjukan yang ditampilkan namun disini para wisatawan dapat berpartisipasi secara aktif seperti memainkan angklung dan membuat angklung sendiri. Sedangkan yang mendapatkan penilaian terendah adalah creative spaces. Mayoritas wisatawan berkunjung ke Saung Angklung Udjo yaitu untuk melihat pertunjukanpertunjukan seni dan budaya yang dikemas secara menarik, sehingga para wisatawan tidak memberikan penilaian yang tinggi terhadap creative spaces di Saung Angklung Udjo.

2. Keputusan berkunjung wisatawan di Saung Angklung Udjo terdiri dari citra destinasi, pengalaman berwisata, tujuan berwisata, waktu dan biaya. Berdasarkan penilaian responden, indikator yang mendapatkan skor ratarata tertinggi adalah pada aspek pengalaman berwisata. Hal tersebut karena paket pertunjukan yang ditawarkan oleh pihak Saung Angklung Udjo sangat menarik sehingga para wisatawan yang berkunjung akan mendapatkan pengalaman berwisata yang menyenangkan. Sedangkan yang mendapatkan penilaian terendah adalah waktu berkunjung, dikarenakan banyaknya wisatawan yang ingin mengunjungi Saung Angklung Udjo sehingga para wisatawan harus menjadwalkan kembali rencana untuk mengunjungi Saung Angklung Udjo.

3. Creative tourism memiliki pengaruh yang signifikan terhadap tingkat kunjungan wisatawan.

\section{DAFTAR PUSTAKA}

Ali Hasan, 2009, Edisi Baru Marketing, Yogyakarta, Media Pressindo.

Asep Hermawan, 2006, Penelitian Bisnis Paradigma Kuantitatif, Jakarta, Grasindo.

Buchari Alma, 2008, Manajemen Pemasaran dan Pemasaran Jasa, Bandung, Alfabeta.

Harun Al Rasyid, 1994, Teknik Penarikan Sampel dan Penyusunan Skala, Bandung, Program Studi Ilmu Sosial Bidang Kajian Utama Sosiologi Antropologi Program Pasca Sarjana UNPAD.
Husein Umar, 2008, Metode Penelitian Untuk Skripsi dan Tesis Bisnis Edisi Kedua, Jakarta, Rajawali Pers

I Gde Pitana dan I Ketut Surya Diarta, 2009, Pengantar Ilmu Pariwisata. Yogyakarta: C.V. Andi Offset.

Ismayanti, 2010. Pengantar Pariwisata. Jakarta: Grasindo.

Kotler, Philip and Amstrong, Gary, 2008, Principles of Marketing $12^{\text {th }}$ edition, New Jersey: Prentice Hall. 2009, Principles of Marketing $13^{\text {th }}$ edition. New Jersey: Prentice Hall

Kotler, Philip dan Kevin Lane Keller. 2009. Marketing Management $13^{\text {th }}$ edition. USA: Prentice Hall.

Lupiyoadi, Rambat dan A. Hamdani. 2008. Manajemen Pemasaran Jasa Edisi 2. Jakarta: Salemba Empat

Morrison, Alastair, M. 2010, Hospitality and Travel Marketing $4^{\text {th }}$ Edition. Thomson Delmar Learning.

Nyoman, S. Pendit. 2003. Ilmu Pariwisata Sebuah Pengajar Perdana. Jakarta: PT. Percetakan Penebar Swadaya.

Yozcu, Ozen Kirant dan Icoz, Orhan. 2010. A Model Proposal on the Use of Creative Tourism Experiences in Congress Tourism and the Congress Marketing Mix. Vol. 8 (3).

Prentice, R. dan Andersen, V. 2003, Festival as creative destination. Annals of Tourism Research, 30(1), 7-30.

Ray, P. H. dan Anderson, S. R. 2000, The cultural creatives, New York: Three Rivers Press.

Raymond, Crispin, 2007, "Creative Tourism New Zealand: The Practical Challenges of Developing Creative Tourism", dalam Richards, Greg \& Wilson, Julie (Eds), Tourism Creativity and Developmen,. New York: Routledge Taylor \& Francis Group.

Renckly. 2002. Guidelines for Planning, Organizing and Conduting Survey.

Richards, G. 2000, World culture and heritage and tourism, Tourism Recreation Research, 25 (1), 9-18.

Richards, G. 2001, ed., Cultural Attractions and European Tourism, Wallingford, CABI.

Richards, G. dan Raymond, C. 2000, Creative Tourism, ATLAS news (23), 16-20.

Richards, G. dan Wilson, J. 2006, Developing creativity in tourist 
experiences: a solution to the social reproduction of culture, Tourism Management 27(6): 1209-23. , 2007, “Tourism development trajectories: From culture to creativity?", dalam Richards, Greg \& Wilson, Julie (Eds), Tourism Creativity and Development, New York: Routledge Taylor \& Francis Group.

2007, "The Creative Turn in Regeneration: Creative Spaces, Spectacles and Tourism in Cities", dalam M. Smith (ed.), Tourism, Culture and Regeneration, Wallingford: CABI, pp. 12-24.

Schiffman, L.G. dan Kanuk, L.L. 2007, Consumer Behavior $9^{\text {th }}$ edition. Pearson International Edition.

Sugiyono, (2008), Metodologi Penelitian Bisnis, Bandung, Alfabeta.
Suharsimi Arikunto, (2006), Prosedur Penelitian: Suatu Pendekatam Praktek, Jakarta, PT. Rineka Cipta.

Undang-undang Republik Indonesia No. 10 tahun 2009

UNESCO, 2006, Towards Sustainable Strategies for Creative Tourism, Mexico, USA.

\section{Website:}

http://www.creativetourism.co.nz/aboutus_o urstory.html

http://www.kabarbisnis.com/life-style/hoteln-travel/2816987-2010

http://kharistya.wordpress.com/2008/02/08

http://mbramantya.wordpress.com/2009/08/ $\underline{28}$

http://catrionacampbell.wordpress.com http://anggorocahyadi.wordpress.com/2010/ 01/27/pengembangan-pariwisata-budayadan-tantangannya/ 